13th International Congress on Mathematical Education

Hamburg, 24-31 July 2016

\title{
COMBINATORIAL REASONING TO SOLVE PROBLEMS
}

\author{
Tom Coenen, Frits Hof and Nellie Verhoef \\ University of Twente
}

This study reports combinatorial reasoning to solve problems. We observed the mathematical thinking of students aged 14-16. We study the variation of the students' solution strategies in the context of emergent modelling. The results show that the students are tempted to begin the problem solving process on the highest level and otherwise have difficulties transitioning from a lower to a higher level of activities. Qualitative analysis revealed some students' preference of the use of formulas, while at the same time other students showed more insight by their systematic approach of the problems, leading to better results. We advocate matching emergent modelling with teaching combinatorial reasoning, stimulating students to create a relational network of knowledge.

\section{INTRODUCTION}

Combinatorial analysis is an appropriate topic in the mathematics curriculum, because it has problems suitable for all grades. Many applications in different fields can be presented in teaching combinatorial analysis (Kapur, 1970). Combinatorial problems stimulate students' construction of meaningful representations, reason mathematically, and abstract and generalize mathematical concepts (Sriraman \& English, 2004). In this study we use emergent modelling indicating students' strategies to solve combinatorial reasoning problems (Gravemeijer, 1999).

\section{THEORETICAL FRAMEWORK}

\section{Mathematical thinking}

Most problems do not have readily available solution methods, and create students' uncertainty regarding how to approach them and what method to employ (Batanero, Navarro-Pelayo, \& Godino, 1997). Mason (2004) distinguished four attention levels: (1) being aware of the whole situation; (2) focus on details and awareness of relations or similarities; (3) focus on properties as attributes that objects might satisfy; and (4) focus on reasoning solely on the basis of properties. Tall (2013) described a general framework for long-term development of mathematical thinking: (1) conceptualembodied knowledge based on perceptions of and reflections on properties of objects; (2) operationalsymbolic knowledge that grows out of the embodied form through - physical - action of the learner into mathematical procedures; and (3) axiomatic-formal knowledge based on formal definitions and proof. Gravemeijer (1999) emphasized students' thinking - related to Mason's attention levels and Tall's framework of development - in terms of levels of activity in a process of emergent modeling:

1. Activity in the task setting, in which interpretations and solutions depend on understanding how to act in the problem setting (often out-of-school settings).

2. Referential activity, in which models-of refer to activity in the setting described in instructional activities.

3. General activity, in which models-for derive their meaning from a framework of mathematical relations. 
4. Formal mathematical reasoning, which is no longer dependent on the support of models-for mathematical activity.

\section{METHOD}

\section{Participants}

Three student groups participated: 5 boys and 9 girls (aged 15-16) with a basic knowledge on tree diagrams; 7 boys and 8 girls (aged 14-15) with no prior education in combinatorial reasoning problems, tree diagrams or probability; 7 boys and 14 girls (aged 14-15) with knowledge how to draw a tree diagram and how to calculate basic probabilities.

\section{Research instrument: field notes of live observations}

The field notes of live observation were in a Lesson Study context deepened by videotapes in order to validate the field notes (Verhoef \& Tall, 2011).

\section{Analysis}

The field notes and the transcribed videotapes were ordered in the levels of activity.

An example of the categorization of student's remarks is given in Table 1. The students are solving the "bookstore question": A bookseller sells top-ten books in order. He lists - from the first four customers who choose a top ten book - which book they decide to buy. How many lists can arise? (the answer is $10 \times 10 \times 10 \times 10$ ). Each student remark is noted, together with the level of emergent modeling. The final column shows if the student's remark is correct or not.

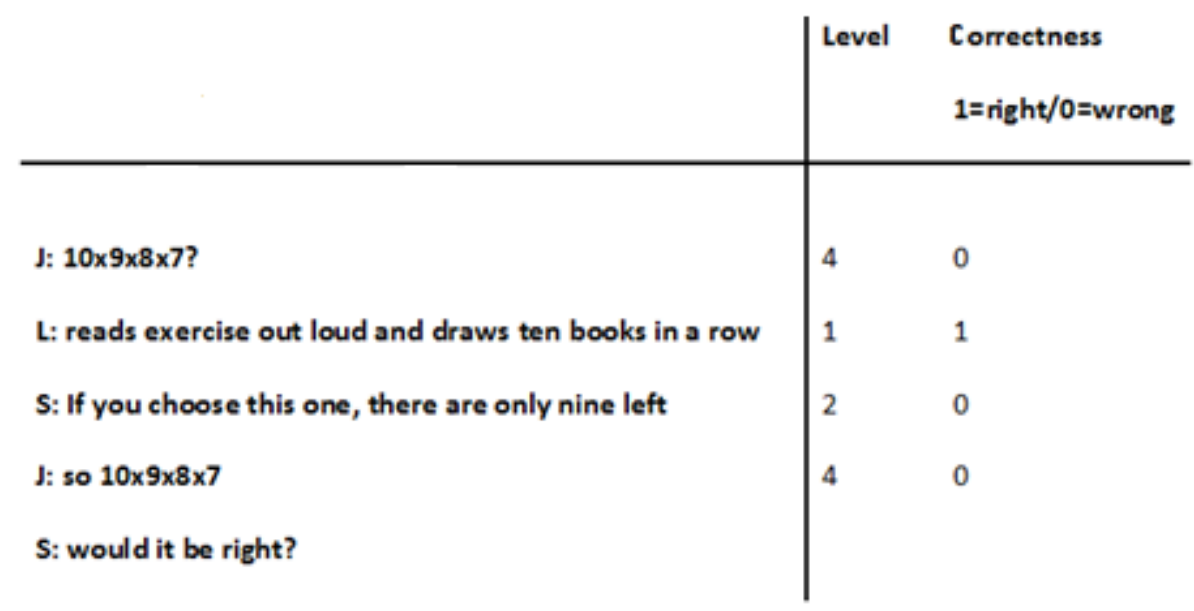

Table 1: Coding of student remarks at levels and quality

\section{RESULTS}

\section{Procedures and formulas}

Lesson 1, one group started with the problem of t-shirts: Going on a holiday, you want to take three of your ten shirts. How many options are there to take three? Student $\mathrm{C}$ had been taught to calculate numbers of combinations with the calculator and found the right answer 120. Student A mentioned that the problem could be solved by using a tree diagram, which would be an action at level 3. Student A was convinced of the correctness of 10x9x8, which she deduced from the tree diagram, and challenged student $\mathrm{C}$ to explain how it is possible that the formula for combinations gives the answer 
of 120 possibilities and 10x9x8 $=720$. Student $\mathrm{C}$ couldn't explain why both answers are not the same: maybe counting lattice paths works? Student A drew an $x$-y grid, tried to calculate the numbers without writing them down, made a mistake calculating and didn't find the correct answer of 120. Now student A was convinced of her solution of 720 possibilities.

After solving the other problems, the students returned to the t-shirt problem. They acknowledged that taking the three t-shirts white, blue and red is the same as taking blue, white and red, but they could not translate this notion to an appropriate solution strategy. Student $\mathrm{C}$ mentioned that probably there are double sets of shirts. According to student A all the problems can be solved with a tree diagrams. But student $\mathrm{C}$ drew an $x$ - $y$ grid and mentioned, without any explanation, that you only have the choice between yes or no. Not being able to agree on a solution, they decided to write down both answers.

\section{Construction of a systematic method}

Lesson 2, student E had the lead. He tried to solve the problem "Ice-cream top three". He wrote down: ice-cream top three. The problem involved an ordered selection without repetition out of six different ice-cream flavours (numbered 1, 2, 3, 4, 5 and 6). Student E started with writing down a 1. He then wrote down 5 and 4, because for scoop 2 and 3, there are 5 x $4=20$ possibilities left. Next, student E wrote down 2. Again he thought that there were 20 possibilities left for scoop 2 and 3 . He repeated this for 3 . Then student $E$ hesitated. He thought that if 2 is on top, there are only $4 \times 3=12$ possibilities left. He continued with 3 on top ( $3 \times 2=6$ possibilities), 4 on top ( $2 \times 1=2$ possibilities), etc. Again student $E$ hesitated. The reason for this hesitation is not clear, but he didn't trust the solution. Student E decided to systematically write down all the possibilities. Student E worked in a structured way, starting with a column containing 123 till 126, followed by 134 till 136, leading up to 156 . The next column started with 234 and so on. He noticed a pattern in the number of possibilities he wrote down: 4,3,2,1 - 3,2,1 - 2,1 - 1, giving him a (false) sense of security. The other students challenged him why for example 132 is not in the columns. Suddenly, student E realized that the structure and combinations belong to the solution of the "ice-cream cup" question (with different flavours) and not to the "ice-cream top three" question. He crossed the top of the page and replaced this with "icecream cup". It is unclear how he concluded this, as he made no remarks about it.

\section{DISCUSSION}

The first example shows that students can start in the highest level and are then unable to check their answer. In the second example we see that student E first uses a mostly formal approach. After choosing the first flavour of ice-cream on top, he calculates the number of possibilities for that one flavour with a multiplication. This multiplication is based on recognition of 'one less left' and can be characterized as an action on the highest level. He repeats this for flavour 2 and 3. The calculation can be continued in a correct way, but he changes his mind. He decreases both factors in the next multiplications - for flavour 2 - with 1. Student E don't express his thoughts about this, but probably again a sort of 'one less each time'-idea makes him do it this way. The decrease is built on a wrong interpretation of the situation that, after flavour 1 is put in the first place, this flavour is not to be chosen in any other top 3. So, although the combinatorial characteristics of order and repetition seem to be considered by the student, which is an action on level 2, the calculation on the fourth level is wrong. Student E doubts himself, and after systematically writing down all possibilities (level 3) 
based on the combinatorial characteristics (level 2) the student reaches insight in what he was doing. His insight is so deep that he can interpret his formal calculation as wrong for the problem and even better, he is able to match the solution to another - the right - question.

\section{CONCLUSION}

In mathematical reasoning students don't automatically develop in line with Tall's (2013) framework and the distinguished levels do not guarantee a correct solution process. The students don't focus on the whole situation but focus on a detail, in line with Mason (2004). Teachers should be aware of the fact that students begin on the highest level without relational understanding and otherwise easily make mistakes going quickly to a higher level in their solution process. Guidance by the teacher seems important. We believe that education focused on relational understanding is of much more value than instrumental instruction (Skemp, 1976). Students are more capable of verifying their strategies and justifying their reasoning when education is built on their individual informal approach (Eizenberg \& Zaslavsky, 2009). We believe that emergent modelling can play an important role in this type of education. Exploration at lower levels can help students to develop a relational network of knowledge and maybe prevent that students start automatically. There seems to be an important role for the teacher: students need guidance to develop a model-of, individually reaching a higher level. We think future research should investigate how teaching combinatorial reasoning could be matched with emergent modelling and what type of guidance is most effective.

\section{References}

Batanero, C., Navarro-Pelayo, V. , \& Godino, J. D. (1997). Effect of the implicit combinatorial model on combinatorial reasoning in secondary school pupils. Educational Studies in Mathematics, 32, 181-199.

Eizenberg, M. M., \& Zaslavsky, O. (2004). Students' verification strategies for combinatorial problems. Mathematical Thinking and Learning, 6(1), 15-36.

Gravemeijer, K. (1999). How Emergent Models May Foster the Constitution of Formal Mathematics. Mathematical Thinking and Learning, 1(2), 155-177.

Kapur, J. N. (1970). Combinatorial Analysis and School Mathematics. Educational Studies in Mathematics, $3(1), 111-127$.

Mason, J. (2004). Doing $\neq$ construing and doing + discussing $\neq$ learning: The importance of the structure of attention. ICME 10 Regular Lecture.

Skemp, R. R. (1976). Relational Understanding and Instrumental Understanding. Mathematics teaching, 77, 20-26.

Sriraman, B., \& English, L. D. (2004). Combinatorial Mathematics: Research into Practice. The Mathematics Teacher, 98(3), 182-191.

Tall, D. O. (2013). How Humans Learn to Think Mathematically. New York: Cambridge University Press.

Verhoef, N.C., \& Tall, D.O. (2011). Lesson study: the effect on teachers' professional development, 35th Conference of the International Group for the Psychology of Mathematics Education (PME), Ankara, Turkey, 10-15 July 2011. 